Revista Iberoamericana. Vol. LXIII, Núm. 180, Julio-Setiembre 1997; 537-541

\title{
LA FILOSOFÍA DE LOS CALIBANES O ¿QUÉ SIGNIFICA UNA “CRÍTICA DE LA RAZÓN LATINOAMERICANA"?
}

\author{
POR \\ SAntiago Castro-Gómez
}

No es posible responder en un espacio tan corto a las profundas y agudas observaciones que Eduardo Mendieta ha colocado sobre la mesa de discusión. Pero quisiera por lo menos referirme a dos aspectos que me parecen importantes: uno tiene que ver con el tipo de lectura que Eduardo realiza de mi texto y el otro con el tipo de crítica que se desprende de esa lectura.

1) Al comienzo de su exposición, Eduardo señala mi deuda con la filosofía trascendental, tanto en la línea formalista de Kant (crítica de la razón pura), como en la vertiente historicista (crítica de la razón histórica) de Dilthey. El proyecto del libro sería delinear la "lógica" que subyace a la construcción discursiva de "América Latina" durante los últimos cien años y mostrar sus límites, sus condiciones de posibilidad. De acuerdo a la lectura de Eduardo, casi todos los discursos elaborados por el pensamiento latinoamericano estarían atravesados por una misma ratio, se asentarían sobre una misma episteme, obedecerían a una sola "metafísica de lo latinoamericano". Mi propósito habría sido, entonces, desenmascarar esa metafísica, sacar a la luz su relación intrínseca con mecanismos institucionales de saberpoder, para lo cual me habría servido del método genealógico de Foucault. La "razón latinoamericana" sería, pues, una construcción hegemónica generada desde (o mediante) las fantasías de los letrados, y la "crítica" de esta razón sería, como en Kant, un ejercicio articulado desde una subjetividad transcendental, desde el mismo tipo de racionalidad desterritorializada que se pretende superar. En su opinión, la "Crítica de la razón latinoamericana" toma (para utilizar la terminología de Habermas) la "perspectiva del observador", abandona la "perspectiva del participante" y reproduce el mismo gesto totalizador que Gayatri Spivak denuncia en los discursos de Foucault y Deleuze: se renuncia a una representación (Vertreten) del "otro", pero sin atreverse a representar (Darstellen) el lugar desde donde se habla.

Eduardo tiene razón cuando repara en algunas resemblanzas de mi proyecto teórico con la filosofía trascendental. La "Crítica de la razón latinoamericana" es ciertamente una analítica de las condiciones de posibilidad de ciertos saberes teóricos sobre Latinoamérica, pero, a diferencia de Kant y de Dilthey, esta crítica no pretende ser un conocimiento desapriorizado de lo a priori. Esto por dos razones: primero, porque no pienso que los discursos europeos que construyeron a Latinoamérica como identidad homogénea desde el siglo XVI hayan seguido una misma "lógica" y se hayan edificado sobre una misma episteme. Tampoco lo hicieron aquellos discursos de la intelectualidad local que imaginaron una 
especie de exterioridad latinoamericana frente a la modernidad europeo-occidental. Como bien lo señala Eduardo mismo, la modernidad - y los discursos que buscaron legitimarlasiguió diferentes caminos no solamente en Europa sino también en América Latina. A una pluralidad espacialmente simultánea de modernidades corresponde una pluralidad de lógicas discursivas, de epistemes que se entrecruzan, se sobreponen o se repelen mutuamente. No hay, pues, una sola "razón latinoamericana", una misma "lógica" (liberadora o cosificante) que explique la emergencia de discursos teóricos sobre Latinoamérica. Mi pretensión no fue, por ello, reconstruir a priori la lógica de una tal razón, sino examinar la manera en que algunos discursos filosóficos sobre América Latina se incrustan en el tejido de algunas sociedades, especialmente en aquéllas en donde se dió una relación más estrecha entre el nacionalismo político de los años treinta al sesenta y los llamados "discursos de identidad". Más que a la filosofía trascendental, mi proyecto debe mucho a la teoría de la sociedad (Weber, Foucault, Habermas), a la crítica literaria (Rama, Beverley, Ramos) y a los estudios culturales latinoamericanos (Brunner, Martín-Barbero, García Canclini).

Esto explica, a su vez, la segunda razón por la cual me distancio de la lectura excesivamente kantiana realizada por Eduardo. El problema que me ocupa no es tanto la lógica formal de los discursos sobre América Latina, sino las prácticas mediante las cuales nuestra intelectualidad imaginó la modernidad europea o norteamericana y generó (a contraluz) una serie de representaciones teóricas sobre "lo latinoamericano". Por esta razón, cuando Eduardo pregunta quién soy y desde dónde hablo, la única respuesta que puedo dar es la siguiente: soy un letrado que habla desde la crisis que experimenta la función social de la intelectualidad en un contexto marcado por la globalización de la cultura. Esta crisis afecta las representaciones masculinas y heroicas que la intelectualidad de los setentas había formado sobre sí misma (el "hombre de letras", la "voz de los que no tienen voz", el "intelectual orgánico", etc.) y que hacían parte del repertorio en el que yo mismo fui socializado. No adopto, entonces, la perspectiva kantiana del observador, sino la del participante en esta crisis. Hablo, para utilizar la expresión de Hugo Achugar, desde la intemperie, desde un espacio atravesado por complejísimas redes globales de causas y efectos que me impiden alcanzar un saber sobre la "totalidad" (A. Giddens, S. Lash, U. Beck). Y desde esta situación me hago la pregunta: ¿cómo es posible, en los albores del siglo XXI, repensar el proyecto de una "filosofía latinoamericana" esbozado por autores como José Vasconcelos, Leopoldo Zea, José Gaos, Arturo Roig, Rodolfo Kusch, Augusto Salazar Bondy, Enrique Dussel y otros muchos? En el libro, es cierto, la respuesta tiene un fuerte sabor deconstructivo (cómo no es posible seguirlo pensando) y quizás a esto se deba la irritación expresada por Eduardo. Pero la crítica de la razón latinoamericana no es un punto de llegada sino un punto de partida. Habrá que examinar en trabajos futuros de qué manera se producen saberes posrepresentacionales y poslatinoamericanos de "lo local", esto es, saberes que emergen en espacios globalizados y que ya no se vinculan por ello a proyectos identitarios de tipo nacionalista, latinoamericanista o tercermundista.

2) En conexión directa con lo anterior se encuentra la objeción hecha por Eduardo en el sentido de que mi libro es ciego frente a los más excelentes logros del pensamiento latinoamericano en el siglo XX, y en especial frente al aporte de las teorías liberacionistas en la década de los setenta. Lo más característico de esta producción teórica, nos dice Eduardo en su libro Latin America and Postmodernity (New Jersey: Humanities Press, 
1997), es el haberse posicionado críticamente frente a la visión desarrollista y eurocéntrica de lamodernidad, reivindicando el propio espacio latinoamericano como locus de enunciación desde el cual es posible articular una modernidad alternativa. Como puede observarse, tal argumentación se acerca mucho a la propuesta teórica del semiólogo argentino Walter Mignolo, frente a la cual tomo distancia crítica en el capítulo sexto de mi libro. Quisiera por ello concentrarme en mis objeciones a las tesis de Mignolo, respondiendo de este modo a las críticas formuladas por Eduardo.

Tal como lo entiendo, el proyecto teórico de Mignolo se propone lograr una reconstrucción poscolonial de la hermenéutica filosófica de Gadamer. Mientras que el pensador alemán se limitó a explorar el problema de la comprensión (Verstehen) en un horizonte monocultural dominado por el humanismo occidental, Mignolo se pregunta cómo es posible acercarse a textos producidos en espacios pluriculturales, atravesados por relaciones colonialistas de poder. Lejos de presuponer, como Gadamer, una tradición cultural en estado de pureza, la hermenéutica se articula como un ejercicio de comprensión en situaciones o en herencias coloniales, tanto por parte del sujeto que interpreta, como por parte de los textos que son interpretados. Cuando el cientista social se identifica biográfica o éticamente con una determinada comunidad excluida, entonces se produce lo que Gadamer llamara una "fusión de horizontes": el intérprete no se aproxima a su objeto como un observador desinteresado, sino que lleva consigo todos los pre-juicios (éticos, teóricos, políticos) que le atan a su propio mundo de la vida, en este caso, a un mundo de la vida marcado por la experiencia de la marginación colonial. El colonialismo funciona, entonces, como un ámbito prefilosófico de identificación mundovital, como una "tradición cultural" desde la cual es posible interpretar la compresión que han tenido los latinoamericanos $-\mathrm{y}$ en especial los letrados-sobre su propio mundo. Aquí se conecta Mignolo con el proyecto de la filosofía de la liberación del joven Dussel, con la antropología filosófica de Rodolfo Kusch y con la hermenéutica ontológica de Edmundo O'Gormann. Éste es el enfoque adoptado en su libro The Darker Side of the Renaissance, donde estudia el período de la conquista de América para mirar qué tipo de "lugares de enunciación" fueron construidos por los sujetos colonizados para interpretarse a sí mismos.

Ahora bien, el modelo que propone Mignolo pareciera funcionar muy bien cuando los textos que toma como objeto de análisis son prácticas simbólicas ligadas a un mundo de la vida no racionalizado. Los calendarios y mapas aztecas, los quipús de los incas y demás formas no alfabéticas de autorepresentación pertenecen ciertamente a un mundo de la vida tradicional, que se reproduce sobre la base de la comunicación cara a cara. Para el estudio de la manera en que tales prácticas funcionaron como estrategias textuales de resistencia frente al colonialismo resulta muy útil el recurso a procedimientos filológicos y semiológicos, como bien lo advierte Mignolo. Pero el problema comienza cuando el pensador argentino desea transladar este modelo al análisis de teorías que se articulan en sociedades complejas del siglo XX, expuestas a procesos muy fuertes de racionalización, como es el caso de las sociedades latinoamericanas de los años setenta. En su opinión, pensadores como Dussel, Kusch, Zea, Ribeiro, Gutiérrez, Freire, Prebisch y Cardoso fueron en realidad hermeneutas de la cultura, filósofos que lograron construir un locus alternativo a las teorías colonialistas de la modernización y el desarrollo. Su participación mundovital en una situación marcada por el imperialismo económico de la posguerra les permitió lograr la "fusión de horizontes", 
recuperar la memoria histórica de los oprimidos e integrarla a una comprensión socioanalítica de su propio mundo. Aquí, en la creación de un espacio genuinamente latinoamericano de enunciación y en el descentramiento del universalismo colonialista de la modernidad, radica el logro más importante de estas teorías. Y precisamente la incapacidad para registrar esta importante contribución a la descolonización de los saberes teóricos en Latinoamérica es, en opinión de Eduardo, la mayor carencia de mi libro.

Pero en realidad, lo que la "Crítica de la razón latinoamericana" pretende mostrar es que la hermenéutica pluritópica de Mignolo es una herramienta necesaria pero no suficiente para evaluar el potencial de los discursos liberacionistas de la década del setenta. Esto por la siguiente razón, puesta ya de relieve por la crítica del joven Habermas a Gadamer: en sociedades complejas, sometidas a la dinámica globalizante de la modernidad, los procesos de reproducción material y cultural se desacoplan del mundo de la vida y dejan de ser coordinados por la comunicación lingüística. Dicho en otras palabras, la acción social pierde su caracter intencional y queda "estructurada" (Giddens) en localidades globales, destradicionalizadas, que se reproducen en base a imperativos de caracter transnacional. Medios deslingüizados como el dinero y el poder asumen la coordinación de las prácticas sociales, incluyendo también, como bien lo vio Foucault, la producción de saberes teóricos. Todo esto significa que el estudio de la producción de teorías sobre "Latinoamérica" y "lo latinoamericano" durante el siglo XX no puede ser llevado a cabo (solamente) con los elementos conceptuales que ofrece la hermenéutica. Pues la construcción de un locus de enunciación teórica, esto es, la producción social de espacios cognitivos de reflexión, no viene determinada solamente por la voluntad autotransparente de los sujetos que interpretan, como piensa Mignolo, sino también por el modo en que están encadenadas las palabras y las cosas al interior de una episteme. No basta, entonces, la pregunta por la "sensibilidad geo-cultural" o por el idioma en que escribe el sujeto que teoriza, pues el acto mismo de la teorización se encuentra atravesado por una "gramática", por un sistema deslingüizado de relaciones que funciona como a priori de la reflexión cognitiva.

En la "Crítica de la razón latinoamericana" me pregunto, entonces, cuál es la "gramática" que organiza la verdad de los discursos liberacionistas en los años setenta y llego a la siguiente conclusión: se trata de la gramática de Próspero, del mismo lenguaje que, en nombre de la civilización y el progreso, justificó la incorporación de América Latina en la dinámica de la modernidad occidental. La teoría de la dependencia, la pedagogía freiriana, la teología de la liberación y la filosofia latinoamericanista, todas estas corrientes buscaban una sola cosa: la realización del proyecto de la modernidad para América Latina. Sólo que ahora sería una modernidad humanística, liberadora, capaz de incluir en su dinámica a los sectores marginados de la sociedad. Para dejar de ser colonias, para salir de la "periferia" y el subdesarrollo, era necesario alcanzar la verdadera modernidad. El lenguaje en el que se articula este proyecto es el mismo de la episteme moderna europea: la postulación de un sujeto único y de un saber universal, la centralidad de la política, el caracter especular de las ciencias, la necesidad de la industrialización, el convencimiento en una progresiva "humanización de la humanidad", la función mesiánica de las vanguardias intelectuales, el logro de la "mayoría de edad" a través del conocimiento, la autonomía del estado-nación. Y el símbolo de estas teorías fue, por supuesto, Calibán, el esclavo que se rebela contra su amo utilizando su propio lenguaje para maldecirle. No estamos frente a una "ruptura 
epistemológica" del discurso europeo de la modernidad, como pretende Mignolo, sino frente a una latinoamericanización o canibalización del mismo. Se trata, pues, de un corpus teórico que, siguiendo a Horacio Cerutti, pudiéramos identificar como una "filosofía de los calibanes".

Pero si no atribuyo a los discursos liberacionistas esa ruptura epistémica que creen ver en ellos Eduardo Mendieta y Walter Mignolo, si no les coloco la etiqueta de discursos "posmodernos" o "poscoloniales", esto no significa que les esté despojando de todo valor. No todos los descentramientos discursivos tienen que tener el caracter de revolución epistemológica. A pesar de estar entretejidos en una gramática que les trasciende, los discursos son articulados por sujetos específicos, que hablan desde localidades concretas y que luchan, desde su propia posicionalidad, por el control de los significados. Este caracter espacial de la discursividad hace que la gramática de los saberes teóricos adquiera ciertas especificidades, que son precisamente las que hay que determinar. Aunque fueron escritos en el mismo lenguaje de Próspero, los mapas de la modernidad elaborados por teóricos y teóricas latinoamericanos desde el siglo XIX variaron mucho con respecto a los utilizados por intelectuales europeos y norteamericanos de la misma época. La crítica literaria de los últimos años ha mostrado, por ejemplo, que la visión de la modernidad contenida en los textos de Sarmiento y Alberdi no es una copia simiesca del imaginario europeo, como hasta hace poco se pensaba. Hay allí una serie de desplazamientos que "transgreden" las reglas del discurso colonial y empujan los discursos hacia las márgenes de la episteme moderna, produciendo una serie de observaciones que resultaría imposible realizar desde el "centro". Pues bien, algo similar ocurre con los discursos liberacionistas de los años setenta en América Latina. Se trataría, entonces, de examinar en qué consiste su caracter de contranarrativas modernas, sin tener que caer para ello en una romantización de "lo latinoamericano" o en la ingenuidad de un tercermundismo epistémico. 
